\title{
Paraplegia
}

\section{Epidemiological Study of Spinal Cord Injury in Spain 1984-1985}

\author{
J. Garcia-Reneses, MD, ${ }^{1}$ R. Herruzo-Cabrera, $M D,{ }^{2}$ M. Martinez-Moreno, \\ MD ${ }^{1}$ \\ ${ }^{1}$ Spinal Cord Injured Unit, 'Medicine Preventive Service, Hospital "Laz Paz", \\ Madrid Spain.
}

\section{Summary}

The authors have studied patients with traumatic and non-traumatic spinal cord injury (SCI) occurring in Spain during 1984 and 1985. They calculate the incidence, and consider the distribution by age, sex, civil state, and the aetiology, lesional level, mortality, job, labour incapacity, dependence independence, social labour reinstatement, transportation from the place of the accident, medical assistance, type of lesion, urinary vesical dysfunction, also re-education, hospital stay, and complications.

In addition, they defined the main risk group for SCI (in respect of age, sex, occupation, etc) in order to address the preventive campaigns to the high risk group. They conclude with the prototype of acute SCI in Spain.

Key words: Spinal cord injury; Epidemiology; Spain, 1984-1985.

The incidence of traumatic spinal cord injury (SCI) in oriental countries is 1.5 per 100000 inhabitants (Chen, 1985), and ranges from 1.26 to 3.32 per 100000 inhabitants in occidental countries (Minaire, 1977).

These data express an occurrence rate less frequent than the real one as they have been calculated from the number of patients hospitalised (Kraus, 1975). If all SCI patients (hospitalised + dead without hospitalisation) the figure would increase by 30 or $40 \%$.

The traumatic SCI occurs more frequently among males than among females, and among those between the ages of 20 and 35 years. It occurs most often among caucasian people and among married or divorced males (Kraus, 1975; Minaire, 1977; Chen, 1985).

Regarding the aetiology of traumatic SCI, traffic accidents comprise more than $50 \%$ of the total cases, the second most common cause being falls (Kraus, 1975; Minaire, 1977; Chen, 1985). 
Due to the lack of published data about the epidemiology of the SCI in Spain, this study was undertaken, providing better information regarding the clinical and social labour features, as well as the incidence. The percentage results of the crude data, can sometimes give a distorted image of the reality if the population at risk is not known. The ratio between these relative numbers is a 'risk ratio' (RR), used to identify the main groups at risk of SCI.

\section{Material and methods}

\section{Concept}

We considered every traumatic or non-traumatic SCI patient occurring during 1984 and 1985, studied in specialised centers in Spanish hospitals.

To discover the incidence and clinical features of SCI, questionnaires were sent to 13 hospitals, including the acute cases occurring during the 2 year period (84-85). The data were returned before September 1986, and were studied in a IBM computer in the hospital 'La Paz' (Madrid).

According to the type of information received we divided the hospitals into 2 groups: the first group consisting of those hospitals from which we had received partial or complete information, and the second group those that only sent us the number of SCI patients registered in those years.

Finally we calculated the RR and their confidence limits 95\% (Rothman, 1987) between different groups with reference to age, sex, jobs, etc. in relation to the overall population of Spain. We consider the minor group as 'base-line', and compare the diverses group in respect of this base-line.

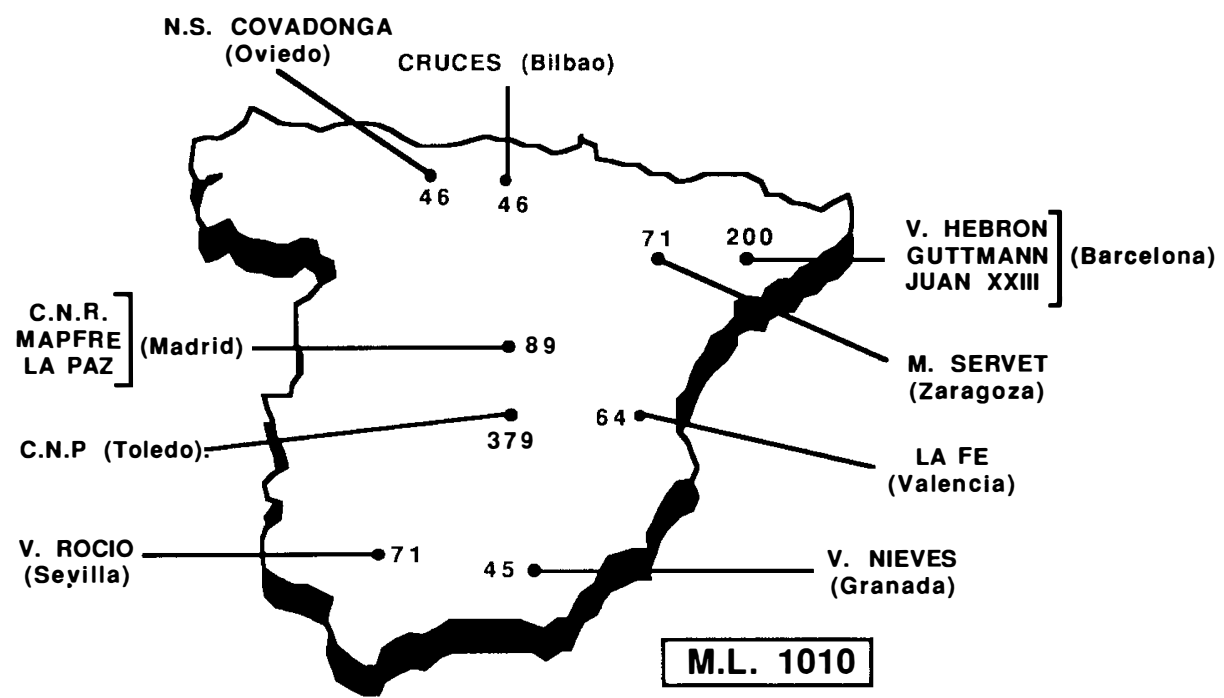

Figure 1 Distribution of cases through the Spanish territory. 


\section{Results}

The 525 (1984) and 485 (1985) registered cases in the hospital centre of the first and second groups respectively make a total of 1010 cases, which indicates an average of 505 acute SCI patients per year in Spain (Fig. 1); thus the global incidence per year would be $1 \cdot 31 / 100000$ inhabitants (for a population of 38.5 million people), being traumatic SCI $61 \%$ and non-traumatic $39 \%$ (SCI traumatic incidence = $0 \cdot 8 / 100000$ and SCI non-traumatic incidence $=0.51100000$ inhabitants).

For the descriptive epidemiology of SCI in Spain we included only cards with complete data (261), approximately $25 \%$ of all cases and their reference hospitals, are set out in Figure 2.

Figure 3 expresses the distribution by age; the average age was $41 \cdot 8 \pm 1 \cdot 2$ years old. The high incidence found between 20 and 30 years of age, bears a relation to the traumatic causes. As for the distribution by sexes, SCI is more frequent in males $(72 \cdot 4 \%)$ than females $(27 \cdot 6 \%)$, that is almost three times more common in males than in females.

SCI patients without children prevail $(63 \cdot 2 \%)$, followed by those who have two children $(16 \cdot 1 \%)$, and then by those who have one or three children $(8 \%)$.

Trauma is the commonest cause of SCI (61\%); and traffic accidents are the most frequent cause of trauma (Fig 4); falls are next in frequency, comprising the $27 \%$ of the total.

The non-traumatic aetiology comprises 39\%; and 44\% result from tumors (Fig. 5), followed by infection, vascular, and others, including spina bifida.

The monthly distribution of SCI increases during Easter and summer. Considering only traffic accidents as the cause of SCI, the curve becomes trimodal, with one more peak at Christmas.

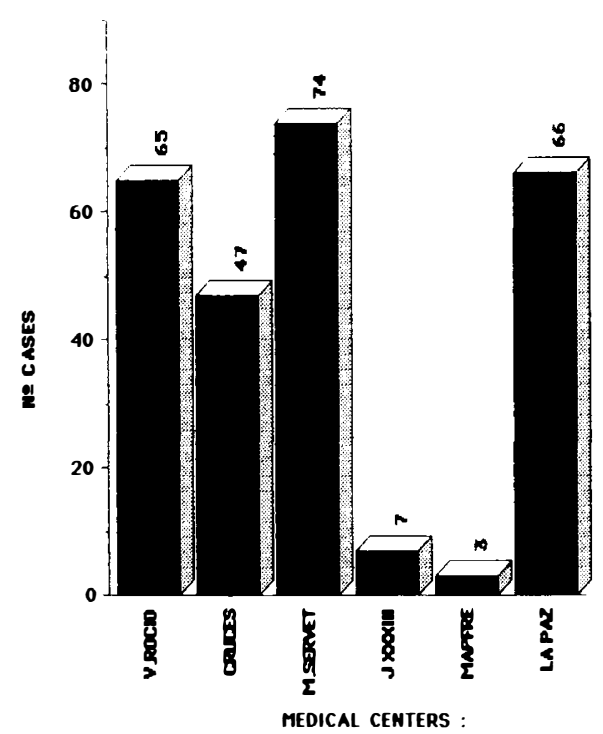

Figure 2 Distribution of cases among different hospitals.

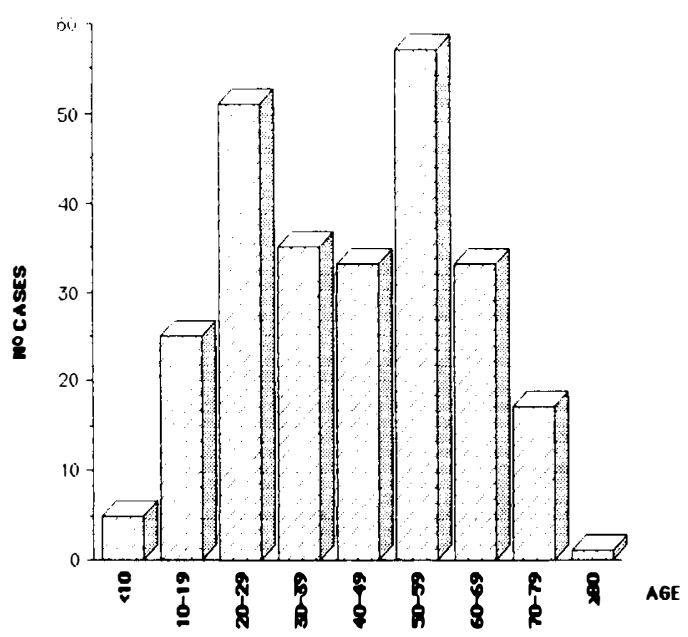

Figure 3 Distribution by ages. 


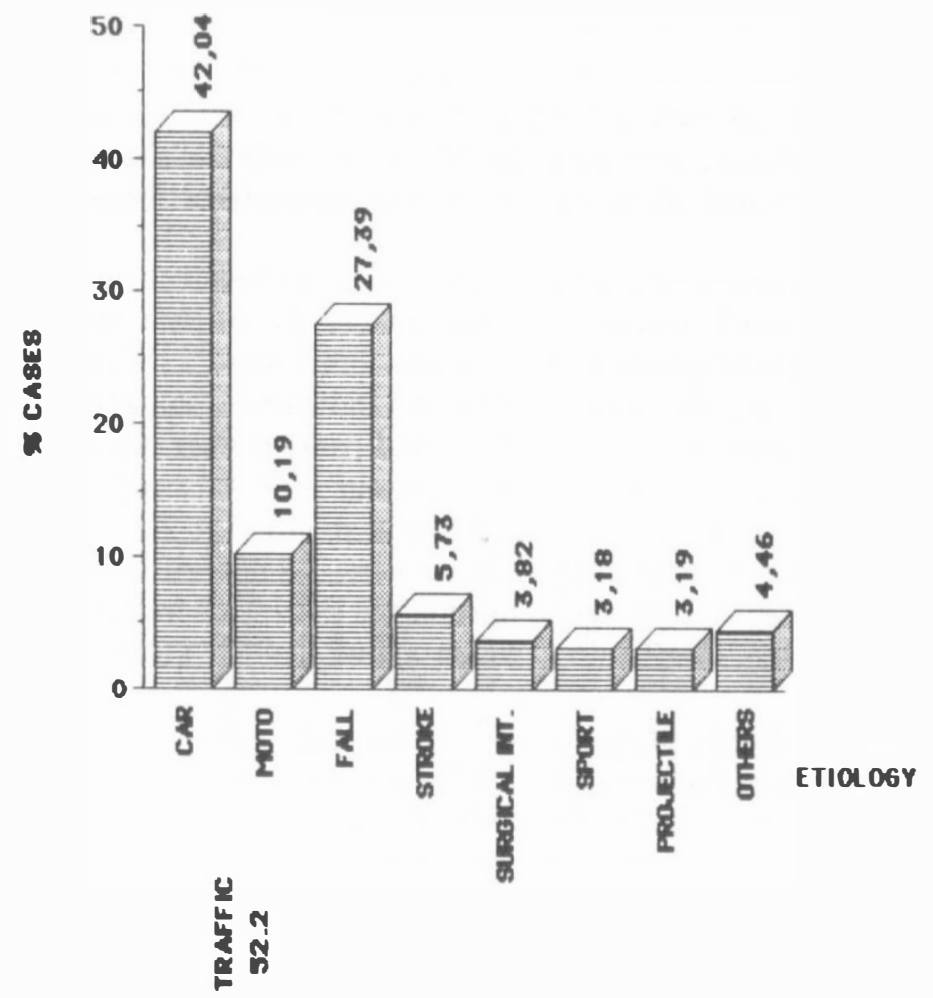

Figure 4 Distribution by traumatic aetiology.

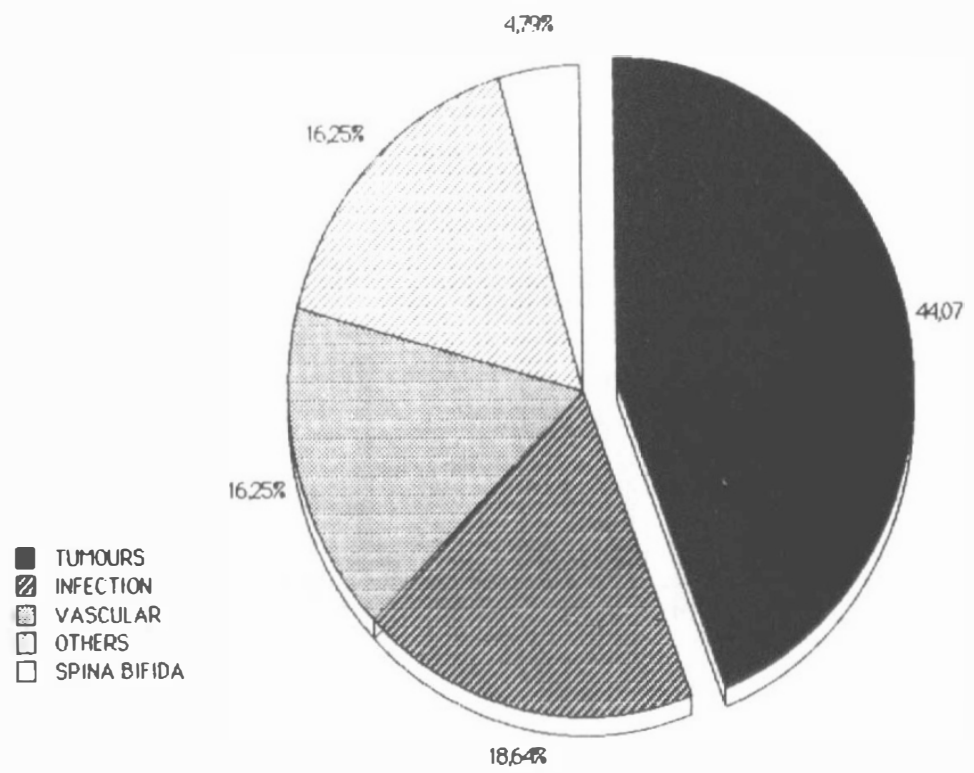

Figure 5 Distribution by medical aetiology. 
Regarding the lesion level, the commonest is cervical (38\%), followed by thoracic $(34 \%)$, lumbar $(16 \%)$, thoracolumbar level $(10 \%)$ and conus medullaris $(2 \%)$. The mortality rate during the period studied was $14 \%$. Traumatic aetiology causes the highest death rate during the first weeks, especially among those with high cervical lesions, and those with a medical aetiology between the third and twelfth month.

SCI patients with lower educational levels are more frequent than those with a higher educational level. Seventy four per cent of the patients studied, worked before the SCI; the predominant type of job was 'other jobs' (22\%), which included pensioners, housewives, etc. Service (21\%) and industrial occupations (20\%) were in second and third place respectively. Most SCI patients were dependent on other people $(55 \%), 36 \%$ were completely autonomous and $9 \%$ needed conventional orthoses (calipers). Social-labour reinstatement shows that $25 \%$ of the patients were in the rehabilitation stage, $36 \%$ of them were still not self-sufficient and only $18 \%$ worked full time. More than one third of the cases were independent and had incomplete lesion, less invalidating, which allowed much quicker social labour reinstatement.

Evacuation from the site of the accident was correct in the $33 \%$, incorrect in the $5.5 \%$, and unknown in the remainder of the patients. The $62 \%$ of traumatic SCI patients were attended to before twenty four hours after the injury, $15 \cdot 7 \%$ after twenty four hours; and we have no data for $22 \%$ of the patients.

According to the type of lesion, the sensory-motor incomplete $\mathrm{SCI}$ is the most frequent type $(49 \%)$, the second being the complete SCI $(38 \%)$. There were few sensory incomplete SCI as well as motor incomplete SCI patients.

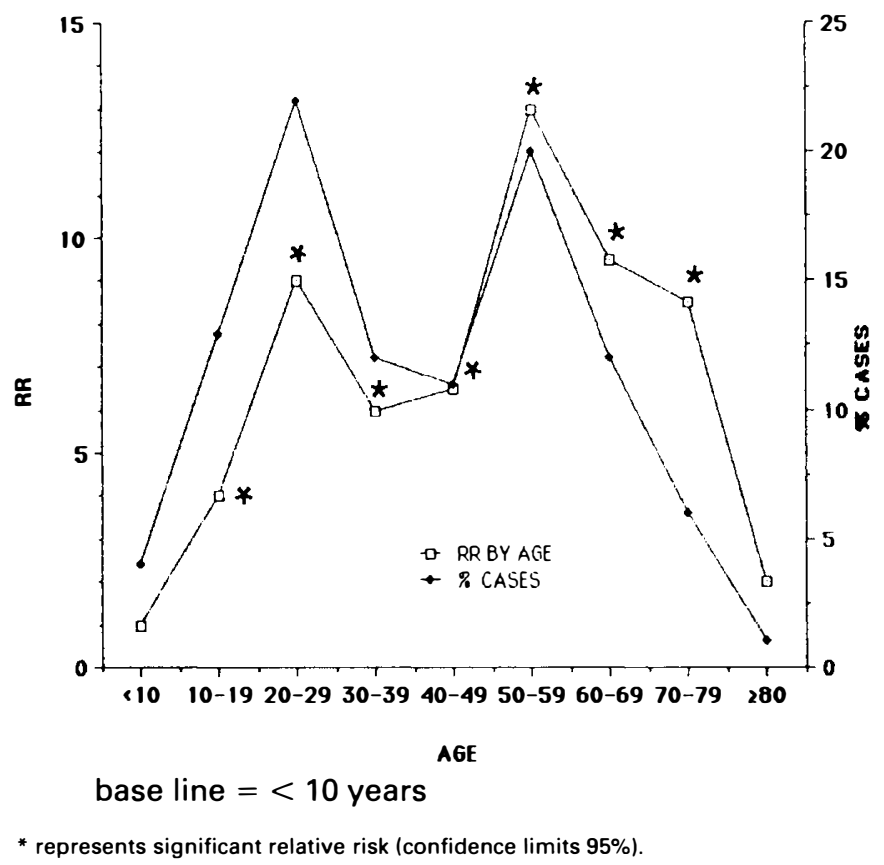

Figure 6 The relative risk of each age group. 
The type of urinary bladder dysfunction found most frequently was the 'supranuclear bladder' (44\%); the infranuclear bladder $10 \%$ and a normal bladder in $29 \%$. Most patients did not require a permanent catheter $(79 \cdot 2 \%)$, thanks to the early vesical re-education, while $17 \cdot 1 \%$ carried over, and $3 \cdot 7 \%$ continued with intermittent autocatheterism. Only $7 \%$ of the SCI patients needed urological surgery.

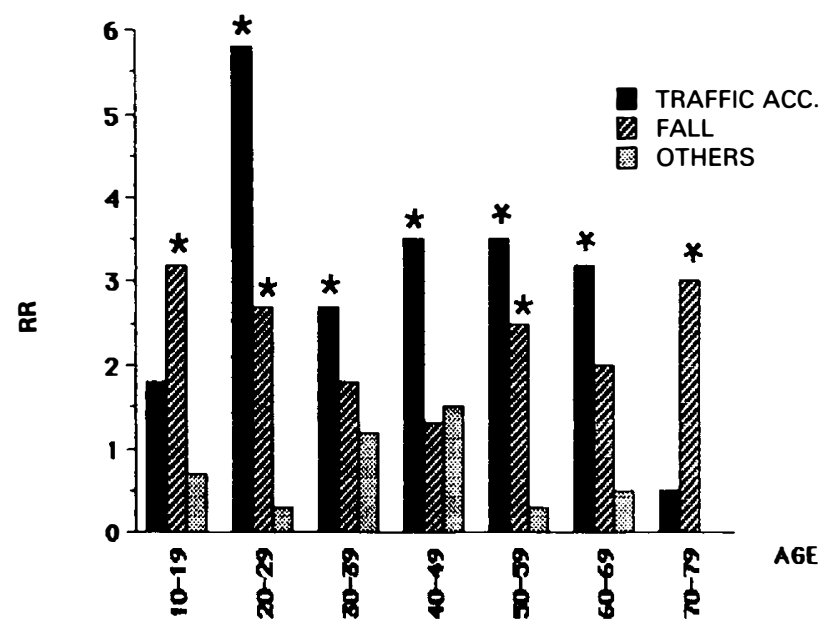

base line $=<10$ years

* represents significant relative risk (confidence limits 95\%).

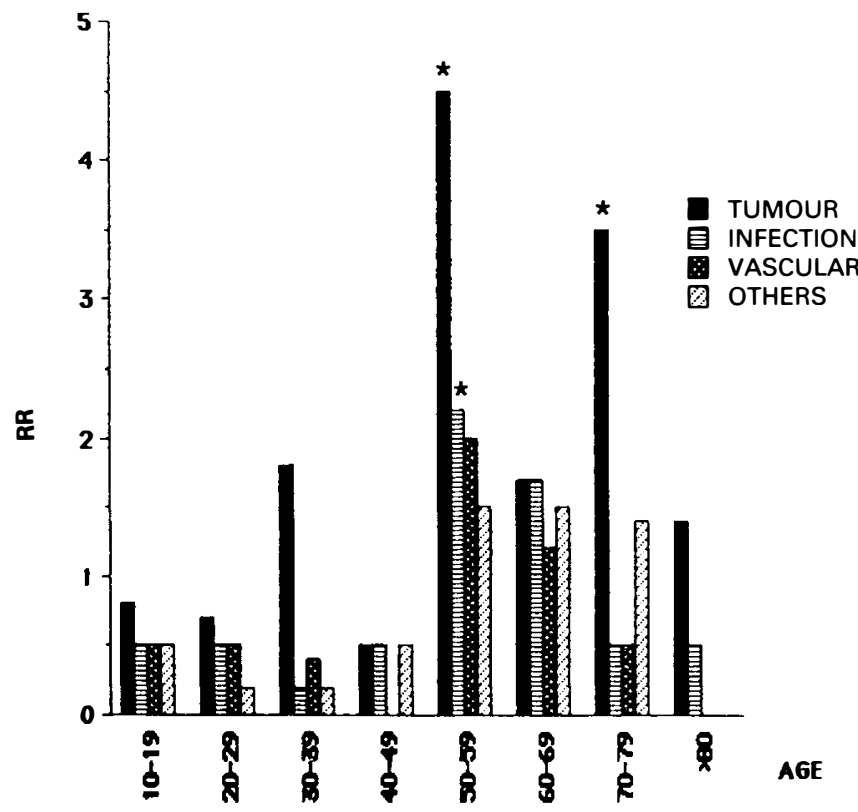

base line $=<10$ years

* represents significant relative risk (confidence limits 95\%).

Figures 7 and 8 Analysis of aetiology in respect of age. 
We observed a higher rate of patients with traumatic SCI but without evident Xray spinal column injury (41\%), followed by fractures-dislocation (36\%) and fracture $(23 \%)$.

The average time of hospitalisation was $4.6 \pm 0.2$ months, the minimum time being 1 month and the maximum 14 months. The rate of SCI patients who required hospital readmission was low $(21,8 \%)$. Most routine reviews $(60 \cdot 5 \%)$ were performed in hospital on an out-patient basis. The most frequent complication in the acute stage was urinary infection, followed by respiratory disorders: related to a high injury level.

We now consider the risk of SCI, between different ages, sexes, jobs, etc.:-

Figure 6 shows the risk ratio (RR) of each age group in respect to the group considered base-line ( $<10$ years). These RR follows a bimodal curve, with two peaks in the 20 and 50 age groups, which expresses a double aetiology, traumatic and non-traumatic respectively.

In the Figures 7 and 8, we analyse in more detail the aetiology in respect of age. The principal cause of the increased risk of SCI in young people, is traffic accidents. Falls are distributed similarly in all those age groups, but are more notable $(\mathbf{9 0 \%})$ in the 70 year age-group. The principal cause of medical SCI in the 50 age-group, are tumors. This is especially high in the 70 year age-group. Figure 9 analyses the RR of SCI in different ages and educational levels: If university students are taken as a reference, we observe that the major RR corresponds to poorer education. There is a relation between secondary level of education and the 10-19 age-group. The RR minor of one among all educational levels in respect to the university level, between 20 and 29 years of age, shows that in this decade,

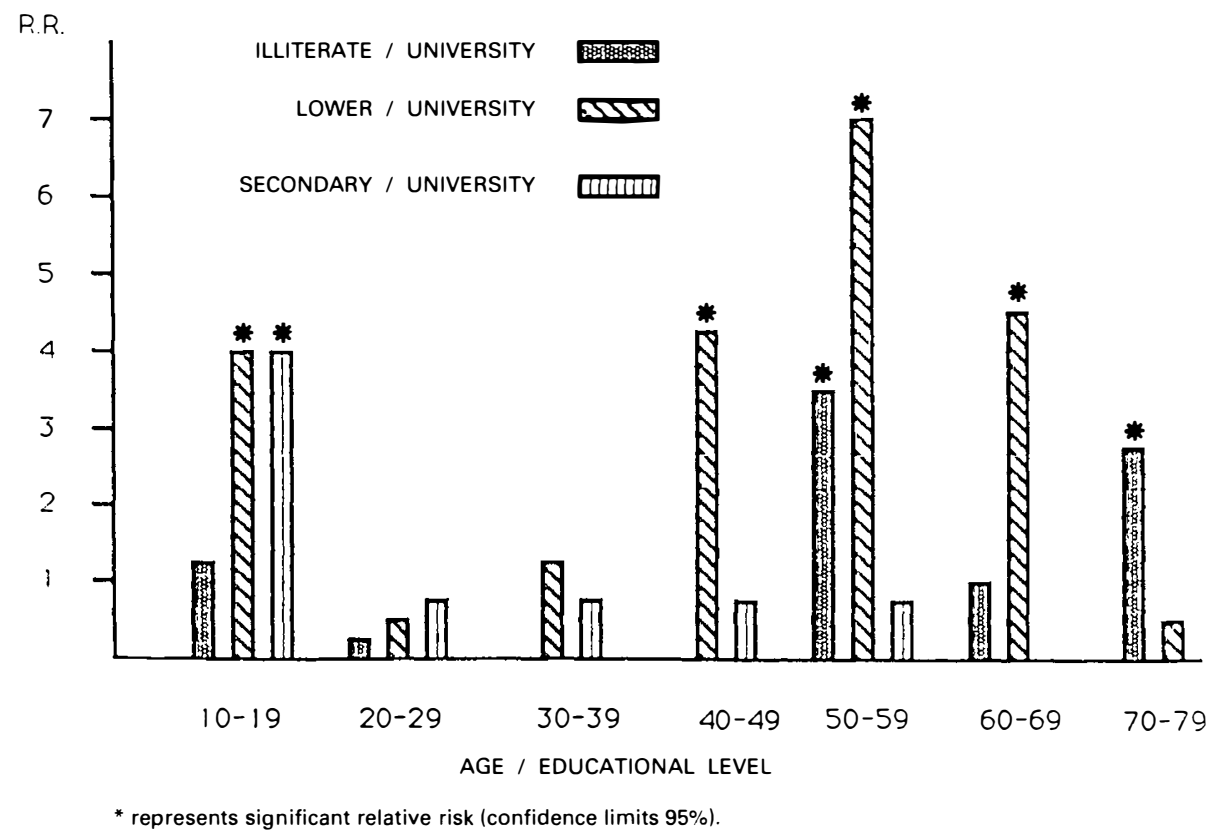

Figure 9 Risk of SCI by age and cultural level. 
those that are more likely to have a SCI are those with a higher cultural level. Finally, the major RR of illiterate people is in the older age groups.

When studying the RR of SCI in different jobs, we obtained many 'zero' answers as we were distributing them by age. For that reason we have limited the presentation and only studied the RR of each job in respect to 'student' (base-line), without distinction of age. Agricultural work stands out to be most at risk for SCI (RR close to 9), followed by 'intermediate' type of professionals' (RR of 8 ) and 'the employers' (RR close to 7). The employers in industry and services also have quite high RR for SCI (6 approximately).

Having studied diverse variables in respect of age, we studied another main aspect, sex, to see which has the highest risk for sustaining a SCI, therefore we will take the feminine sex group as 'base-line': Men have a higher risk for SCI at all ages (Fig. 10) with RR that oscillates between 2 and 5 who mentioned a global risk of 4 . Ages between 20 and 40 stand out among the rest. Nevertheless both sexes have a similar risk in the elderly (RR close to 1 ). This major frequency of SCI in men occurs with all educational levels. The risk increases with the cultural level and in all types of jobs (Fig. 11), especially in industry, intermediate professionals and managers. Both sexes have the same incidence in agricultural work and 'others' (retired, unemployed, etc.).

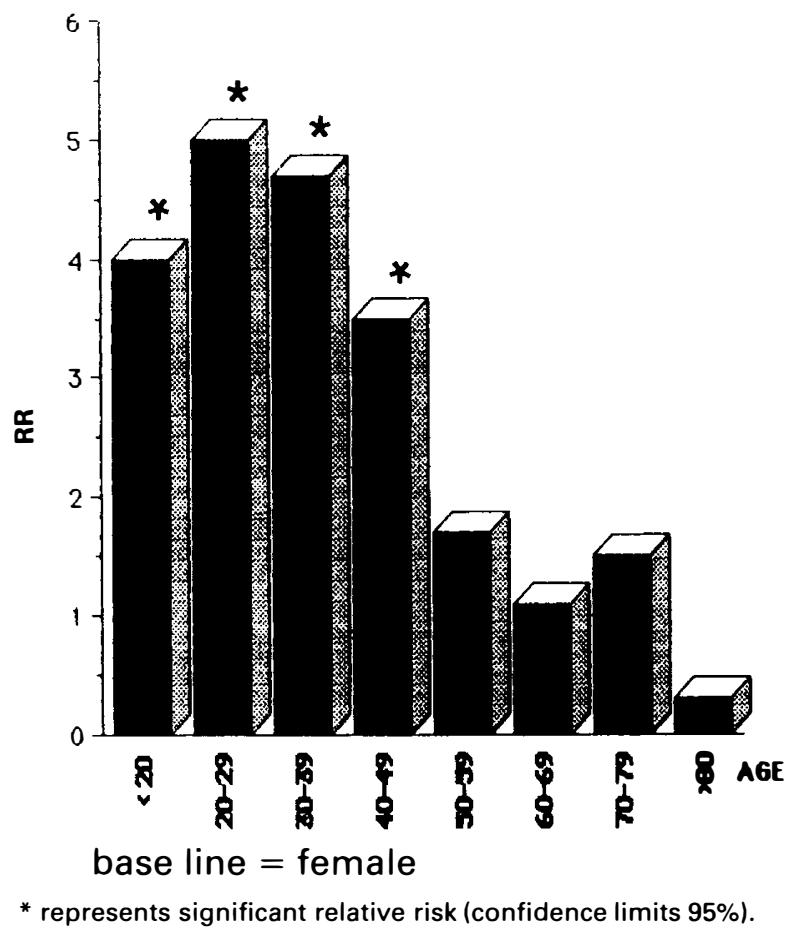

Figure 10 Relative risk analysis between sex and age. 


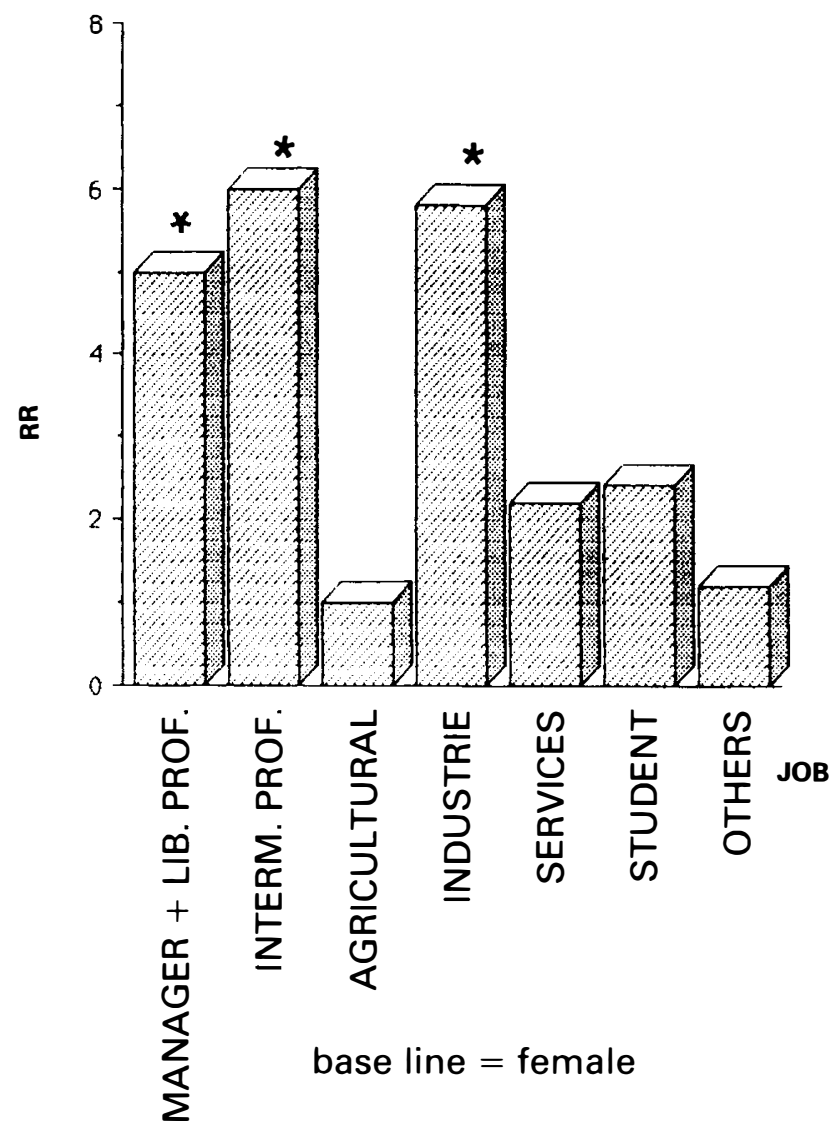

* represents significant relative risk (confidence limits $95 \%$ ).

Figure 11 Relative risk analysis between sex and job.

\section{Discussion}

The rate of the occurrence of SCI in Spain occupies an intermediate place compared to that of other countries (Chen, 1985; Kraus 1975; Kraus, 1980). Nevertheless, in order to make an exact evaluation of the relative situation of Spain in relation to other countries, it would be necessary to calculate the incidence, not starting from the global data, but from the standardised appraisal by ages (Lilienfield, 1983).

The distribution of our population by age is similar to that reported in the studies carried out by Minaire (1977), and Kraus (1975), respectively. But, in our study we found a greater number of married people than did Kraus (1975), since this study only refers to traumatic SCI patients.

The monthly distribution of traumatic SCI, evolves almost parallel to the increase of traffic accidents (Altozano-Moraleda, 1985). This point is very important for the primary prevention of SCI.

The mortality is greater than that found by other authors (Chen, $1985 ; 6 \%$ ), but 
that study only includes traumatic SCI, and we also include non-traumatic SCI for instance from malignant tumors, and thus the higher mortality rate.

In the analysis of the RR by age, we found an increase of the RR in the 20 year group, principally determined by traffic accidents. This has also been described by authors like Minaire (1977), Chen (1985) and Myron (1985). On the other hand, falls are distributed more frequently in the older age group. Kraus (1975) and Gerard (1980) also refer to the importance of this cause in SCI in the elderly. But the principal cause of SCI in the years 50-70 are tumors.

The sex of the patient is very important in SCI. The increased risk in males is due to the higher incidence of traumatic SCI, which coincides with the reports of several authors (De Vivo, 1980; Fine, 1980; Girard, 1975; Kraus, 1980; Kurtzke, 1975). Besides, both sexes suffer equally from SCI of non-traumatic aetiology.

The risk of SCI evolves inversely with the educational level in older people. This is correlated with the social changes that occurred in the years 1960 and 1970 with the population influx from the rural areas to the cities (Pumarola, 1983). People with a low cultural level had to perform jobs previously unknown to them (more labour accident risks), and required to live in a strange and little humanised environment, such as occurs in large cities, where there is a greater tendency for falls, traffic accidents, etc, especially in the more advanced age groups.

\section{Conclusion}

The incidence of SCI in Spain per year is $1 \cdot 31 / 100000$ inhabitants, being $0 \cdot 8 / 100000$ inhabitants and $0.51 / 100000$ inhabitants for traumatic and nontraumatic causes respectively.

- SCI presented as a complete lesion in $38 \%$ of patients.

-Urinary bladder dysfunction occurred in the $71 \%$ of patients, and vesical reeducation was complete in $79 \cdot 2 \%$.

-The average length of hospitalisation was 4.6 months. The principal complication was urinary tract infection.

- The main group at risk of SCI are males, especially about the age of 30 years, who suffer traumatic SCI (traffic accidents mainly), as well as both sexes in the $\mathbf{5 0}$ to 60 age group (SCI of non-traumatic aetiology), and finally the group constituted by older than 70 years old with traumatic SCI (falls) or non-traumatic (tumors) with an almost equal incidence between both aetiologies.

The major risk of SCI also exists in those with a lower culture level and whose work involves more physical risk due to the work itself (agriculture), the necessity of travelling (middle rank employees, employers, etc) especially among males, except for those in the agricultural sector in which both sexes appear to have an equal risk.

-For all of the information obtained, campaigns for prevention of SCI will be addressed to those groups whose jobs and ages are at high risk for SCI, in order to reduce industrial and traffic accidents (or even better, to school boys and girls before the ages when they are due to begin employment). We must not forget that everything done for the greater humanisation of large cities can reduce traffic accidents and falls, especially in the elderly. Secondly, these campaigns would include the general prevention of cancer and its known and avoidable risk factors 
(tobacco, alcohol, etc.). We also tend to get a more effective preventive-sanitary covering of the population for the detection and early treatment of cancers.

\section{Acknowledgements}

The authors are grateful to our colleagues for their help and encouragement: Rehabilitation Services of the following Hospitals: Virgen del Rocio, Sevilla; Cruces, Bilbao; Miguel Servet, Zaragoza; Juan XXIII, Tarragona and Mapfre, Madrid, Spain.

\section{References}

Altozano Moraldea JM, Borobia Fernandez C, Montenegro Serrano J et al. 1985 Accidentes de tráfico. Fano 649:8-61.

Chen CF, LIEN IN 1985 Spinal cord injuries in Taipei, Taiwan. Paraplegia 23:364-370.

DeVivo MJ, Fine PR, MAeTz M, STOVER SL 1980 Prevalence of spinal cord injury. A reestimation employing life table techniques. Archives Neurology 37:707-708.

Fine RR, KUhLEMEIER KJ, DEVIVo MJ et al. 1980 Spinal cord injuries: an epidemiologic perspective. Paraplegia 17:237-250.

Girard R, Minaire P, CaAtanier M et al. 1975 Incidence of traumatic spinal cord lesions. Fournal of Chronic Disease 28:471-492.

Girard R, Minaire P, CaAtanier M et al. 1980 Spinal cord injury by falls: Comparison between suicide and accidental cases. Paraplegia 18:381-385.

KRAUS JF, FRANTI CE, RIGGINS RS et al. 1975 Incidence of traumatic spinal cord lesions. Fournal Chronic Disease 28:471-492.

KRAUS JF 1980 A comparison of recent studies on the extent of the head and spinal cord injury problem in the United States. Fournal of Neurosurgery 53:511-518.

KURTZKE JF 1975 Epidemiology of spinal cord injury. Experimental Neurology 48:163-236.

LILIENFELD AM, LILIENFELD DE 1983 Fundamentos de epidemiología. Fondo Educativo Interamericano México.

Minaire P, CaAtanier M, Girard R et al. 1977 Epidemiology of spinal cord injury in Rhône-Alpes France. Paraplegia 16:76-77.

Pumarola Busquet A, Piedrola Gil G, Gonzalez Fuste et al. 1983 Medicina preventiva y social. Higiene y sanidad ambiental. Ed Amaro. Madrid.

Rothman J 1987 Fundamentos de epidemiología. Ed Díaz de Santos. Madrid. 